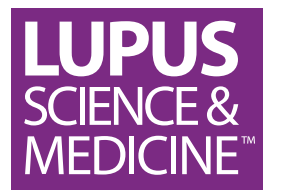

\title{
Vitamin D deficiency is common and associated with increased C-reactive protein in children and young adults with lupus: an Atherosclerosis Prevention in Pediatric Lupus Erythematosus substudy
}

\author{
Angela Byun Robinson, ${ }^{1}$ Vin Tangpricha, ${ }^{2}$ Eric Yow, ${ }^{3}$ Reut Gurion, ${ }^{1}$ \\ Grace A McComsey, ${ }^{4}$ Laura E Schanberg, ${ }^{5}$ for the APPLE investigators
}

To cite: Robinson $A B$, Tangpricha V, Yow E, et al. Vitamin $D$ deficiency is common and associated with increased C-reactive protein in children and young adults with lupus: an

Atherosclerosis Prevention in Pediatric Lupus

Erythematosus substudy. Lupus Science \& Medicine 2014;1:e00011.

doi:10.1136/lupus-2014000011

Received 9 January 2014 Revised 4 April 2014 Accepted 5 April 2014

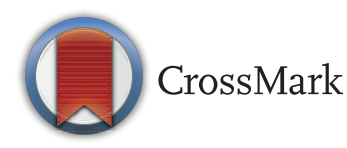

For numbered affiliations see end of article.

Correspondence to Dr Angela Byun Robinson; angela.robinson@ uhhospitals.org

\section{ABSTRACT}

Objective: Epidemiological associations suggest vitamin $D$ may play a role in inflammation and atherosclerosis. Using frozen serum and data from the Atherosclerosis Prevention in Pediatric Lupus Erythematosus (APPLE) trial, we assessed associations between 25 -hydroxyvitamin $D[25(\mathrm{OH}) \mathrm{D}]$ and measures of systemic lupus erythematosus (SLE) disease activity and cardiovascular risk.

Methods: Baseline APPLE serum samples were used to measure $25(\mathrm{OH}) \mathrm{D}$ levels. Logistic regression models for vitamin $D$ deficiency $[25(\mathrm{OH}) \mathrm{D}$ levels $<20 \mathrm{ng} / \mathrm{mL}$ ] were constructed using baseline variables collected as part of the trial, including race, season, latitude, disease duration, disease activity, high-sensitivity C-reactive protein (hsCRP), proteinuria, fasting lipids and carotid intima medial thickness (CIMT).

Results: Samples were available from 201 of 221 APPLE subjects; $61 / 201$ (30\%) had vitamin D deficiency at baseline. In univariable analysis, baseline vitamin $D$ deficiency was associated with season

$(p<0.01)$, minority status $(p<0.01)$, body mass index $(p=0.04)$, duration of SLE $(p<0.01)$, SLICC damage index $(p=0.04)$, hsCRP $(p<0.01)$, mean-max CIMT $(p=0.01)$, LDL-cholesterol $(p=0.03)$ and timed urine protein $(p=0.03)$. In multivariable modelling, vitamin $D$ deficiency was associated with age, latitude, season, minority status, proteinuria and hsCRP. Conclusions: Vitamin D deficiency is common in paediatric lupus and is independently associated with elevated hSCRP, a marker of inflammation that predicts cardiovascular disease risk. Although association is not proof of causation, this association is novel in the paediatric SLE population and suggests that vitamin $D$ deficiency may contribute to heightened inflammation and cardiovascular risk in this population.

Trial register number: NCT00065806.

\section{KEY MESSAGES}

Vitamin D deficiency is common in paediatric lupus.

- In this population, vitamin D deficiency is associated with not only traditional risk factors, but also chronic inflammation markers such as hsCRP.

\section{INTRODUCTION}

Over the last three decades, systemic lupus erythematosus (SLE)-related mortality has decreased in all areas except for cardiovascular disease (CVD). ${ }^{1}$ Women with SLE less than 40 years of age are at a 50-fold increased risk of myocardial infarction compared with control populations. ${ }^{2}$ This increase in risk cannot be attributed solely to traditional cardiovascular risk factors; both immune and vascular pathology in SLE are postulated to contribute. ${ }^{3} 4$

Vitamin D deficiency has emerged as a potential risk factor for CVD. ${ }^{5}$ Vitamin D status is mainly determined by the level of circulating 25-hydroxyvitamin D [25( $\mathrm{OH}) \mathrm{D}]$, which is converted into an active secosteroid hormone, 1,25-dihydroxyvitamin $\mathrm{D} \quad[1,25$ $\left.(\mathrm{OH})_{2} \mathrm{D}\right]$, by the kidney and cells of the immune system such as B cells, T cells and dendritic cells. The activated hormone then regulates transcription of several inflammatory cytokines. ${ }^{6}$ Studies have shown that vitamin $\mathrm{D}$ deficiency (widely defined as a serum $25(\mathrm{OH}) \mathrm{D}$ concentration less than $20 \mathrm{ng} / \mathrm{mL}$ ) is common in SLE and has been associated with photosensitivity, fatigue, renal disease, disease activity and proteinuria. ${ }^{7-11}$ 
In vitro, $1,25(\mathrm{OH})_{2} \mathrm{D}$ blocks dendritic cell differentiation, lowers interleukin-12 secretion and modulates Band T-lymphocyte proliferation and function. ${ }^{12-15}$ Differentiation of dendritic cells and release of type I interferon are important in the pathogenesis of SLE. ${ }^{16}$

In epidemiological studies of the general population, low vitamin $\mathrm{D}$ levels have been associated with CVD, hypertension, diabetes, HDL and LDL-cholesterol, and surrogate measurements of cardiovascular risk such as coronary artery calcification and carotid intima media thickness (CIMT). ${ }^{5}$ One prospective study found that serum $25(\mathrm{OH}) \mathrm{D}<15 \mathrm{ng} / \mathrm{mL}$ had a multivariableadjusted HR of 1.62 (95\% CI 1.11 to $2.36, p=0.01$ ) for incident CVD events. ${ }^{17}$ Another study of subjects with dyslipidemia found that the addition of vitamin $\mathrm{D}$ to atorvastatin synergistically lowered total and LDL-cholesterol levels. ${ }^{18}$ There are no studies that have evaluated the relationship between vitamin $\mathrm{D}$ status, inflammation and subclinical vascular disease in paediatric subjects with lupus.

The Atherosclerosis Prevention in Pediatric Lupus Erythematosus (APPLE) trial was originally designed to prospectively assess the effect of atorvastatin on progression rate of CIMT in 221 children and young adults (aged 1021 years) with SLE. ${ }^{19}$ Subjects were randomised to 36 months of atorvastatin (10-20 mg/day based on weight) versus placebo treatment in addition to their ongoing treatment of SLE. Primary results showed no significant difference in mean-mean CIMT progression between treatment and placebo groups; however, the primary results confirmed that children and adolescents with SLE have subclinical atherosclerosis with CIMT progression rates greater than reported in healthy children and children with familial hyperlipidaemia. ${ }^{19}$ The objective of this subanalysis was to use samples prospectively obtained during participation in the APPLE study to evaluate the relationship between vitamin D status and baseline measures of inflammation and CVD risk in children with SLE.

\section{MATERIALS AND METHODS}

Subjects

Participants in the 3-year APPLE trial were randomised to placebo or atorvastatin, and CIMT progression was measured. The design and methods of the APPLE trial have been reported previously. ${ }^{19}$ SLE was classified by American College of Rheumatology criteria, and participants were enrolled from 21 North American centres. Patients were excluded from the study if they had baseline fasting total cholesterol $>350 \mathrm{mg} / \mathrm{dL}$, familial hypercholesterolaemia, nephrotic syndrome, renal insufficiency, liver disease or were pregnant or nursing. Participants were randomised to daily atorvastatin (>50 kg: $10 \mathrm{mg} /$ day, increasing to $20 \mathrm{mg} /$ day at day $30 ; \leq 50 \mathrm{~kg}: 10 \mathrm{mg} /$ day). Hydroxychloroquine, low-dose aspirin, multivitamins containing folate and American Heart Association Therapeutic Lifestyle Changes diet were recommended. Treatment for SLE was determined by the treating paediatric rheumatologist.

\section{CIMT measurements}

Two baseline CIMT examinations were performed using an ultrasound protocol described previously. ${ }^{20}$ All ultrasound scans were centrally read (Ward A. Riley Ultrasound Center, Wake Forest University School of Medicine, Winston-Salem, North Carolina, USA) by a single experienced reader using Image Pro software (Media Cybernetics, Bethesda, Maryland, USA). Standardised longitudinal B-mode images were collected for three arterial segments defined as the common carotid artery, the carotid bifurcation and the proximal $10 \mathrm{~mm}$ of the internal carotid artery. For a set of 68 studies reread to evaluate intrareader reliability, the intraclass correlation coefficient was 0.74 (95\% CI 0.61 to 0.83 ) for mean-mean common and 0.71 (95\% CI 0.56 to 0.81 ) for mean-max CIMT measurements. The combination of three arterial segments, two walls and two sides of the neck provided a set of 12 CIMT measurement sites, each imaged from four angles. The 12 maximum CIMT values were then averaged to determine the mean-max CIMT over near and far walls of the right and left common carotid artery, carotid bifurcation and internal carotid artery. For each of the four measurement sites in the common carotid artery, a mean CIMT value defined as the average of the four angle-specific mean CIMTs was also calculated. The four mean CIMT values were then averaged to determine the mean-mean common CIMT.

\section{Markers of atherosclerosis and SLE disease severity}

Other assessments including fasting lipid levels and disease activity scores (SELENA-SLEDAI, SLICG, PedsQL 4.0) were obtained as previously described. ${ }^{20}$ IRB approval was obtained for the original APPLE trial and additionally for this secondary analysis.

\section{Serum 25(OH)D determinations}

Frozen serum collected from the APPLE trial at baseline stored in $-80^{\circ}$ freezers were shipped in one batch to the laboratory of Dr Vin Tangpricha at Emory University. Serum $25(\mathrm{OH}) \mathrm{D}$ was measured by chemiluminescent assay using the IDS iSYS automated system (Fountain Hills, Arizona, USA). Intraassay and interassay coefficients of variation for serum $25(\mathrm{OH}) \mathrm{D}$ were $1.8-4.0 \%$ and $10.1-13.0 \%$, respectively. The laboratory participates in a vitamin $\mathrm{D}$ external quality control assessment schema (http://www.deqas.org) and the National Institute of Arthritis (NIH) standard quality control programme for vitamin $\mathrm{D}$ and tested proficient in the measurement of $25(\mathrm{OH}) \mathrm{D}$ during the study period.

\section{Statistical analysis}

All statistical analyses were performed using SAS V.9.2 statistical software (SAS Inc, Cary, North Carolina, USA). All statistical tests were two-sided with $p$ values less than 0.05 considered significant for this analysis. This study was an analysis of baseline characteristics only and did not evaluate subjects over time after randomisation. 
Baseline characteristics were summarised using descriptive statistics, with continuous data presented as means and SDs and dichotomous or ordinal data presented as percentages. Differences between groups were assessed with either the $\chi^{2}$ test or the non-parametric Wilcoxon's test. For baseline serum $25(\mathrm{OH}) \mathrm{D}$ level and vitamin D deficiency $[25(\mathrm{OH}) \mathrm{D}$ levels $<20 \mathrm{ng} / \mathrm{mL}]$ respectively, models were constructed to examine each relationship with a select group of baseline variables or predictors. These predictors include variables collected as part of the APPLE trial including (1) known risk factors for vitamin D deficiency, including race, season, latitude, multivitamin use, body mass index and socioeconomic status; (2) SLE-specific factors including duration of illness, disease activity, high sensitivity C-reactive protein (hsCRP) and proteinuria; and (3) traditional cardiovascular risk factors including fasting lipids and baseline CIMT. To examining the relationship between each predictor and the continuous outcome of serum $25(\mathrm{OH}) \mathrm{D}$ level, separate linear regression models were estimated for each predictor. For continuous predictors, scatter plots with an overlay of locally weighted scatterplot smoothing (LOESS) were constructed to examine the relationships between continuous variables and the outcome of serum $25(\mathrm{OH}) \mathrm{D}$. Transformations were considered for gross departures from linearity. A multivariable linear regression model was constructed with the outcome serum $25(\mathrm{OH}) \mathrm{D}$ level at baseline and the list of selected predictors. A backwards elimination variable selection procedure was implemented to reduce the variables in the model to be the most impactful and parsimonious. Finally, a multivariable logistic regression model was constructed with the outcome vitamin D deficiency at baseline and the list of selected predictors. To examine the relationship between each predictor and the binary outcome of vitamin D deficiency at baseline, separate logistic regression models were estimated for each predictor. For continuous predictors, plots of restricted cubic splines were constructed to examine the relationships between continuous variables and the outcome of vitamin D deficiency. Transformations were considered for gross departures from linearity. A backwards elimination variable selection procedure was implemented to reduce the numbers of variables in the model to be the most impactful and parsimonious.

\section{RESULTS}

\section{Baseline characteristics}

A total of 201/221 (91\%) of APPLE subjects had available baseline samples and were included in the analysis. Participants were recruited from 21 North American sites. Participants were $83 \%$ female, $51 \%$ Caucasian, 27\% African-American, 23\% Hispanic and had a median age of 16 (IQR 14 to 19) years at entry into the study. Median duration of SLE was 24 (IQR 7 to 45) months. Mean SLEDAI score at time of entry was 4 (IQR 2 to 6) points; $75 \%$ had had a SLICC score of 0.
Children with active nephrotic syndrome, hypercholesterolaemia and renal insufficiency were excluded, but $41 \%$ had a history of glomerulonephritis, $33 \%$ had a history of hypertension and median creatinine clearance was 134 (IQR 119 to 155 ) $\mathrm{mL} / \mathrm{min}$. Median fasting total cholesterol levels were $148 \mathrm{mg} / \mathrm{dL}$. Overall, $73 \%$ of subjects reported taking multivitamins and $67 \%$ reported taking vitamin $\mathrm{D}$ supplementation at baseline. Table 1 shows the baseline demographics.

\section{Vitamin D status}

Overall, 61/201 (30\%) had vitamin D deficiency at baseline and $139(69 \%)$ had levels $<30 \mathrm{ng} / \mathrm{mL}$, indicating vitamin D insufficiency; 12 subjects $(6 \%)$ had levels less than $10 \mathrm{ng} / \mathrm{mL}$ indicating severe vitamin $\mathrm{D}$ deficiency. Median serum 25(OH)D levels were $25.8 \mathrm{ng} / \mathrm{mL}$ (IQR 18.2 to 31.7$)$.

\section{Associations with vitamin D status}

\section{Univariable analysis}

Vitamin D deficiency as a dichotomous outcome was associated with first quarter season, African-American race, longer SLE disease duration, increased proportions of participants with SLICC damage index scores greater than 0 , increased baseline hsCRP and increased LDL-cholesterol (see table 1). Evaluation of vitamin D status as a continuous outcome did not change associations with season, race, disease duration, SLICC damage index and baseline hsCRP. The association with LDL-cholesterol trended towards significance $(p=0.06)$. Log transformation of hsCRP improved model fit but did not change the underlying association $(p<0.01)$. Using vitamin D status as a continuous outcome, log transformation of timed urine protein improved model fit with a significant association between vitamin $\mathrm{D}$ deficiency and increasing proteinuria $(p=0.03)$. With linear regression, lower vitamin $\mathrm{D}$ status was associated with increased mean-max CIMT $(p=0.01)$ and body mass index percentile $(\mathrm{p}=0.04)$.

\section{Multivariable analysis}

Using the same variables, a multivariable logistic model was constructed using backward, forward and stepwise variable selection procedures and compared with backward and forward results. In all three selection procedures, vitamin D deficiency was associated with age, latitude, season, minority status and hsCRP. Duration of SLE was included in initial variable selection along with age, but was not selected for the final model. Timed urine proteinuria trended towards significance $(\mathrm{p}=0.06)$ and was included in all models (see table 2).

\section{DISCUSSION}

In this secondary analysis of the baseline evaluation of paediatric subjects with SLE enrolled into a large randomised trial, we showed significant independent associations between vitamin $\mathrm{D}$ deficiency and age, body mass 
Table 1 Baseline characteristics of APPLE cohort by vitamin D status

\begin{tabular}{|c|c|c|c|c|}
\hline Variable & $\begin{array}{l}25(O H) D \geq 20 \mathrm{ng} / \mathrm{mL} \\
\mathrm{n}=140\end{array}$ & $\begin{array}{l}25(\mathrm{OH}) \mathrm{D} \\
<20 \mathrm{ng} / \mathrm{mL} \\
\mathrm{n}=61\end{array}$ & $\begin{array}{l}\text { All patients } \\
\mathrm{n}=201\end{array}$ & p Value \\
\hline Female & $114(81.4 \%)$ & $53(86.9 \%)$ & $167(83.1 \%)$ & 0.34 \\
\hline Age, years (SD) & $15.4(2.6)$ & $16.3(2.8)$ & $15.7(2.7)$ & 0.05 \\
\hline Latitude (SD)* & $39.5(3.4)$ & 38.9 (3.0) & 39.3 (3.3) & 0.09 \\
\hline \multicolumn{5}{|l|}{ Seasont } \\
\hline 1st quarter & 18 (12.9\%) & $18(29.5 \%)$ & 36 (17.9\%) & \multirow[t]{4}{*}{$<0.01$} \\
\hline 2nd quarter & 36 (25.7\%) & $18(29.5 \%)$ & $54(26.9 \%)$ & \\
\hline 3rd quarter & $43(30.7 \%)$ & $9(14.8 \%)$ & $52(25.9 \%)$ & \\
\hline 4th quarter & 43 (30.7\%) & $16(26.2 \%)$ & $59(29.4 \%)$ & \\
\hline \multicolumn{5}{|l|}{ Race } \\
\hline White & $84(60.0 \%)$ & $18(29.5 \%)$ & $102(50.7 \%)$ & \multirow[t]{5}{*}{$<0.01$} \\
\hline Black & 27 (19.3\%) & 27 (44.3\%) & 54 (26.9\%) & \\
\hline Asian & 15 (10.7\%) & $4(6.6 \%)$ & $19(9.5 \%)$ & \\
\hline Native American & $3(2.1 \%)$ & $0(0.0 \%)$ & $3(1.5 \%)$ & \\
\hline Native Hawaiian & 4 (2.9\%) & $1(1.6 \%)$ & $5(2.5 \%)$ & \\
\hline Hispanic or Latino & $29(20.7 \%)$ & $18(29.5 \%)$ & 47 (23.4\%) & 0.18 \\
\hline History of smoking & $3(2.1 \%)$ & $3(4.9 \%)$ & $6(3.0 \%)$ & 0.37 \\
\hline Postpubertal & $91 / 114(79.8 \%)$ & $46 / 53(86.8 \%)$ & $137 / 167$ (82.0\%) & 0.28 \\
\hline \multicolumn{5}{|l|}{ Household income } \\
\hline$<25000$ & $32 / 131(24.4 \%)$ & $25 / 56(44.6 \%)$ & $57 / 187(30.5 \%)$ & \multirow[t]{6}{*}{0.13} \\
\hline $25-49999$ & $36 / 131(27.5 \%)$ & $15 / 56(26.8 \%)$ & $51 / 187$ (27.3\%) & \\
\hline 50-74999 & $25 / 131(19.1 \%)$ & $6 / 56(10.7 \%)$ & $31 / 187$ (16.6\%) & \\
\hline 75-99999 & $19 / 131(14.5 \%)$ & $5 / 56$ (8.9\%) & $24 / 187$ (12.8\%) & \\
\hline $100-149999$ & $12 / 131(9.2 \%)$ & $4 / 56(7.1 \%)$ & $16 / 187$ (8.6\%) & \\
\hline$>150000$ & $7 / 131(5.3 \%)$ & $1 / 56(1.8 \%)$ & $8 / 187(4.3 \%)$ & \\
\hline BMI percentile (SD) & $72.3(24.0)$ & $71.5(28.0)$ & $72.1(25.2)$ & 0.77 \\
\hline Duration of lupus, months (SD) & $26.7(26.1)$ & $38.8(33.2)$ & $30.4(28.9)$ & 0.01 \\
\hline SLEDAI (SD) & $4.2(3.9)$ & $5.3(4.4)$ & $4.5(4.0)$ & 0.10 \\
\hline SLICC $=0$ & $111(79.3 \%)$ & $40(65.6 \%)$ & $151(75.1 \%)$ & 0.04 \\
\hline Hypertension & $42 / 135(31.1 \%)$ & $23 / 60(38.3 \%)$ & 65/195 (33.3\%) & 0.32 \\
\hline Glomerulonephritis & $52 / 139(37.4 \%)$ & $29 / 61(47.5 \%)$ & $81 / 200(40.5 \%)$ & 0.18 \\
\hline Creatinine clearance (SD) & $136.5(27.0)$ & $143.8(40.6)$ & $138.7(31.8)$ & 0.31 \\
\hline Timed urine protein, $\mathrm{mg} / 24 \mathrm{~h}(\mathrm{SD})$ & $142.0(212.2)$ & $365.5(790.8)$ & $214.6(491.5)$ & 0.07 \\
\hline \multicolumn{5}{|l|}{ Serologies } \\
\hline Lupus anticoagulant & $50 / 135(37.0 \%)$ & $18 / 55(29.5 \%)$ & $68 / 190(35.8 \%)$ & 0.23 \\
\hline Anticardiolipin ab & $59 / 137(43.1 \%)$ & $27 / 59(45.8 \%)$ & $86 / 196(43.9 \%)$ & 0.57 \\
\hline dsDNA & $113 / 140(80.7 \%)$ & $50 / 61(82.0 \%)$ & $163 / 201$ (81.1\%) & 0.73 \\
\hline Corticosteroid usage & $116(82.9 \%)$ & $47 / 60(78.3 \%)$ & $163 / 200(81.5 \%)$ & 0.45 \\
\hline ACE inhibitor usage & $32 / 140(22.9 \%)$ & $17 / 60(28.3 \%)$ & $49 / 200(24.5 \%)$ & 0.41 \\
\hline Vitamin D & $94 / 140(67.1 \%)$ & $39 / 60(65.0 \%)$ & $133 / 200(66.5 \%)$ & 0.77 \\
\hline Calcium & $87 / 140(62.1 \%)$ & $33 / 60(55.0 \%)$ & $120 / 200(60.0 \%)$ & 0.35 \\
\hline Baseline hsCRP (SD) & $2.2(7.5)$ & $4.6(10.4)$ & $2.9(8.4)$ & $<0.01$ \\
\hline Homocysteine (SD) & $7.3(2.6)$ & $7.7(3.8)$ & $7.4(3.0)$ & 0.93 \\
\hline \multicolumn{5}{|l|}{ Lipids (SD) } \\
\hline Total cholesterol & $152.9(39.3)$ & $158.6(36.5)$ & $154.7(38.5)$ & 0.16 \\
\hline HDL cholesterol & 47.1 (13.8) & 43.5 (10.8) & $46.0(13.0)$ & 0.24 \\
\hline LDL cholesterol & 83.6 (31.8) & $91.6(30.0)$ & $86.0(31.4)$ & 0.03 \\
\hline Triglycerides & $111.4(54.4)$ & $123.5(92.9)$ & $115.2(68.6)$ & 0.93 \\
\hline Lipoprotein A (SD) & $21.8(26.5)$ & $24.3(22.4)$ & $22.6(25.3)$ & 0.22 \\
\hline Baseline mean-mean common CIMT & $0.467(0.042)$ & $0.471(0.044)$ & $0.468(0.042)$ & 0.57 \\
\hline Baseline mean-max CIMT & $0.580(0.055)$ & $0.590(0.056)$ & $0.583(0.055)$ & 0.23 \\
\hline
\end{tabular}

Bold denotes $p$ values less than 0.05 to indicate statistical significance.

*Latitude is defined as the degree of latitude of the subject study centre. Latitude ranged from 32 to $48^{\circ}$.

†Season is defined as follows: 1 st 1/1-3/31, 2nd 4/1-6/30, 3rd 7/1-9/31, 4th 10/1-12/31.

APPLE, Atherosclerosis Prevention in Pediatric Lupus Erythematosus; CIMT, carotid intima medial thickness; hsCRP, high-sensitivity C-reactive protein. 
Table 2 Multivariable logistic modelling of vitamin D deficiency [serum $25(\mathrm{OH}) \mathrm{D}<20 \mathrm{ng} / \mathrm{mL}$ ]

\begin{tabular}{lclr}
\hline & $\begin{array}{c}\text { Odds } \\
\text { ratio }\end{array}$ & 95\% Cl & p Value \\
\hline Age & 1.28 & 1.09 to 1.50 & $\mathbf{0 . 0 0 2}$ \\
Latitude* & 0.87 & 0.76 to 0.99 & $\mathbf{0 . 0 3 4}$ \\
Season $\dagger$ & & & $<0.050$ \\
$\quad$ 1st quarter & 2.83 & 0.87 to 9.23 & 0.084 \\
2nd quarter & 1.23 & 0.45 to 3.36 & 0.685 \\
$\quad$ 3rd quarter & 0.57 & 0.19 to 1.75 & 0.327 \\
Minority status $¥$ & 17.47 & 5.22 to 58.48 & $<0.001$ \\
Log timed urine & 2.47 & 0.96 to 6.34 & 0.060 \\
proteinuria & & & \\
Log hsCRP & 1.40 & 1.07 to 1.83 & $\mathbf{0 . 0 1 5}$ \\
\hline
\end{tabular}

Bold denotes $p$ values less than 0.05 to indicate statistical significance.

*Latitude is defined as the degree of latitude of the subject study centre. Latitude ranged from 32 to $48^{\circ}$.

†Season is defined as follows: 1 st $1 / 1-3 / 31$, 2nd 4/1-6/30, 3rd $7 / 1-9 / 31$, 4th 10/1-12/31, with 4th quarter as the referent season.

$\ddagger$ Minority status is all races/ethnicities compared with the referent of white, non-Hispanic.

hsCRP, high-sensitivity C-reactive protein.

index, season, minority status and latitude, which are consistent with larger epidemiological studies of the general population. Clearly, increased age, increased body mass index, late season, decreased UV exposure and darker skin pigmentation are well-established independent risk factors for vitamin D deficiency, and many of these risk factors were present in the APPLE cohort. At entry into APPLE, most study participants had established SLE disease with a mean duration of 30 months. Almost $75 \%$ of participants reported taking regular multivitamins, and $67 \%$ reported taking vitamin D supplementation. Despite this, our results indicate that vitamin D deficiency continues to be relatively common in paediatric SLE with $30 \%$ of participants having deficient levels of vitamin D $(25(\mathrm{OH}) \mathrm{D}$ less than $20 \mathrm{ng} / \mathrm{mL})$ and $69 \%$ having insufficient levels of vitamin D $(25(\mathrm{OH}) \mathrm{D}$ less than $30 \mathrm{ng} / \mathrm{mL}$ ), consistent with findings from Kamen et al and others. ${ }^{7-10}$

In addition to the traditional risk factors of race, season and body mass index, this study highlights associations between vitamin D deficiency and SLE-specific factors such as disease duration, SLICC damage index, hsCRP and proteinuria. Usage of corticosteroids and ACE inhibitors were not associated with vitamin D deficiency in this study. In our analysis, we found no association between corticosteroid usage or dosage by weight and vitamin D levels in this cohort; however, we did not have enough data to look at history of corticosteroid usage in this population. In the original analysis of the APPLE baseline data, there was an association between corticosteroid usage and baseline CIMT, but the relationship was non-monotonic and nonlinear with different steroid dosages by weight. ${ }^{20}$ In previous cross-sectional studies of SLE, serum $25(\mathrm{OH}) \mathrm{D}$ levels less than $20 \mathrm{ng} / \mathrm{mL}$ were associated with photosensitivity, fatigue, renal disease, increased body mass index and elevated SLEDAI scores. ${ }^{7-10}$ In a recent prospective SLE cohort, treatment with vitamin D2 over 128 weeks to an increase of $20 \mathrm{ng} / \mathrm{mL}$ in $25(\mathrm{OH}) \mathrm{D}$ level was associated with a $21 \%$ decrease in the odds of having a high SELENA-SLEDAI score and a $15 \%$ decrease in the odds of having significant proteinuria, although the clinical improvement was relatively modest. ${ }^{21}$ We have previously reported that children with SLE and proteinuria have increased vitamin $\mathrm{D}$ binding protein in their urine, which correlates with decreased serum albumin and serum 25(OH)D. ${ }^{11}$ Decreased serum vitamin D binding protein may diminish the half-life of serum $25(\mathrm{OH}) \mathrm{D}$ since $25(\mathrm{OH}) \mathrm{D}$ is protein-bound and crosses the cell membrane complexed with vitamin $\mathrm{D}$ binding protein. The association between vitamin $\mathrm{D}$ deficiency and timed urine protein in this cohort is also consistent with this relationship.

The relationship between vitamin $\mathrm{D}$ status and the inflammatory marker CRP has been previously described in adults with SLE, specifically in the LAPS study, a randomised study of atorvastatin in adults with lupus. ${ }^{22}$ In LAPS, a $25(\mathrm{OH}) \mathrm{D}$ level of greater than $21 \mathrm{ng} / \mathrm{mL}$ was associated with lower cross-sectional baseline CRP levels. CRP is associated with higher SLE disease activity measured by physician's global assessment or SLEDAI and has been associated with increased serositis and arthritis. ${ }^{23-25}$ In newly diagnosed patients with SLE, hsCRP levels correlate with disease activity. ${ }^{26}$ For the first time in paediatric lupus, we show an independent association between vitamin D deficiency and elevated hsCRP, which persisted despite adjusting for traditional vitamin $\mathrm{D}$ deficiency risk factors. Although the cross-sectional design of this study precludes causal inferences, the association between vitamin $\mathrm{D}$ and hsCRP suggests that vitamin $\mathrm{D}$ may play a role in the chronic inflammation seen in SLE.

Although univariate modelling showed a relationship between increased mean-max CIMT and vitamin D deficiency, this association disappeared in the multivariate model. It is possible that adjusting for hsCRP, other confounders, or a loss of power due to limited sample size diminished the ability to see a difference in the multivariate model. In further analysis of the 3-year progression of CIMT seen during the study, we found evidence of interaction between vitamin $\mathrm{D}$ status and the effect of atorvastatin on mean-max CIMT progression over 3 years. ${ }^{27}$ The sample size in this analysis is relatively small for multivariate analysis of CIMT; however, the APPLE study is the largest North American trial cohort of paediatric SLE to date and larger numbers of participants with detailed clinical characterisation linked to available serum samples are not available for analysis. The associations seen between vitamin D, hsCRP and CIMT suggest that vitamin $\mathrm{D}$, through a role in the inflammatory pathway, may be associated with CIMT. Given that this is an exploratory analysis, these results should be interpreted cautiously as hypothesis generating rather than 
hypothesis testing. This scenario mirrors recent data from another chronic inflammatory condition, treated HIV infection, where vitamin D deficiency was also associated with inflammatory markers and CIMT. ${ }^{28}$

In summary, vitamin $\mathrm{D}$ deficiency is common in paediatric lupus and is independently associated with elevated hsCRP, a marker of inflammation, which predicts CVD risk. In this population, vitamin $\mathrm{D}$ deficiency was associated with traditional risk factors such as season, race, latitude, and age, but also with SLE-specific factors including hsCRP and proteinuria. Observed association differences between univariable and multivariable modelling may be related to confounding or loss of power and requires further study. The association between vitamin $\mathrm{D}$ deficiency and hsCRP is novel in paediatric lupus and suggests that vitamin D deficiency may independently contribute to heightened inflammation and cardiovascular risk in this high-risk population. Further analyses of the APPLE cohort are ongoing to examine possible interactions between vitamin $\mathrm{D}$ deficiency and atorvastatin in the 3-year CIMT progression rates and hsCRP.

\author{
Author affiliations \\ ${ }^{1}$ Department of Pediatrics, Rainbow Babies and Children's Hospital/Case \\ Medical Center, Cleveland, Ohio, USA \\ ${ }^{2}$ Department of Medicine, Emory University School of Medicine, Atlanta, \\ Georgia, USA \\ ${ }^{3}$ Duke Clinical Research Institute, Durham, North Carolina, USA \\ ${ }^{4}$ Department of Medicine and Pediatrics, Case Medical Center, Cleveland, \\ Ohio, USA \\ ${ }^{5}$ Department of Pediatrics, Duke University Medical Center, Durham, North \\ Carolina, USA
}

Collaborators The following participated in this study by enrolling patients at sites or by performing study procedures at sites: Stacy Ardoin, Esi Morgan Dewitt, C Egla Rabinovich, Janet Ellis, Kelly Mieszkalski, Janet Wootton (Duke University Medical Center, Durham, North Carolina), Peter Chira, Joyce Hsu, Tzielan Lee, Christy Sandborg, Jan Perea (Stanford University School of Medicine, Palo Alto, California), Beth Gottlieb, Patricia Irigoyen, Jennifer Luftig, Shaz Siddiqi, Zhen Ni, Marilynn Orlando, Eileen Pagano (Cohen Children's Medical Center, New Hyde Park, New York), Andrew Eichenfield, Lisa Imundo, Deborah Levy, Philip Kahn, Candido Batres, Digna Cabral (Morgan Stanley Children's Hospital of New York-Presbyterian, New York, New York), Kathleen A. Haines, Yukiko Kimura, Suzanne C. Li, Jennifer Weiss, Mary Ellen Riordan, Beena Vaidya (Hackensack University Medical Center, Hackensack, New Jersey), Emily von Scheven, Michelle Mietus-Snyder (University of California at San Francisco Medical Center, San Francisco, California), Earl Silverman, Lawrence Ng (Hospital for Sick Children, Toronto, Ontario, Canada), Suzanne Bowyer, Susan Ballinger, Thomas Klausmeier, Debra Hinchman, Andrea Hudgins (Indiana University School of Medicine, Indianapolis, Indiana), Marilynn Punaro, Shirley Henry, Shuzen Zhang (Texas Scottish Rite Hospital for Children, Dallas, Texas), Nora G. Singer, Elizabeth B. Brooks, Stacy Miner, Nancy Szabo, Lisabeth Scalzi (University Hospitals/ Case Medical Center, Cleveland, Ohio), David Sherry, Libby Dorfeld, Sarajane Wilson, Jenna Tress (Children's Hospital of Philadelphia, Philadelphia, Pennsylvania), Deborah McCurdy, Tatiana Hernandez, Jyotsna Vitale (University of California Los Angeles Medical Center, Los Angeles, California), Marisa Klein-Gitelman, Angela Kress, Nicole Lowe, Falguni Patel (Children's Memorial Hospital, Chicago, Illinois), Carol Wallace, Stephanie Hamilton (Seattle Children's Hospital and Regional Medical Center, Seattle,

Washington), Richard Silver, Katie Caldwell, Diane Kamen (Medical University of South Carolina, Charleston, South Carolina), Linda Wagner-Weiner, Becky Puplava, Atanas Lonchev (University of Chicago, Chicago, Illinois), Gloria Higgins, Monica Bacani (Nationwide Children's Hospital, Columbus, Ohio), Hermine Brunner, Cynthia Rutherford, Jamie Meyers-Eaton, Shannen Nelson, Alexei Grom (Cincinnati Children's Hospital Medical Center, Cincinnati, Ohio),
Larry Jung, Teresa Conway, Lacey Frank, Lori Kuss (Creighton University Medical Center, Omaha, Nebraska), Jenny Soep, Hazel Senz (University of Colorado, Aurora, Colorado), Ann Reed, Thomas Mason, Jane Jaquith, Diana E. Paepke-Tollefsrud (Mayo Clinic, Rochester, Minnesota).

Contributors Each individual named as an author meets the Uniform Requirements for Manuscripts submitted to Biomedical Journals criteria for authorship

Funding APPLE supported by the NIH (National Institute of Arthritis and Musculoskeletal and Skin Diseases contract N01-AR-2-2265), the Edna and Fred L. Mandel Jr. Center for Hypertension and Atherosclerosis, and Pfizer, which provided atorvastatin and matching placebo. Secondary analysis supported by the Rainbow Babies and Children's Hospital Pediatrics Pilot Award and the NIH (National Institute of Arthritis and Musculoskeletal and Skin Diseases contract 5P30-AR-047363-12). The investigators have no conflicts of interest to disclose except that LES received consulting fees from Pfizer (less than $\$ 10000$ ) and Pfizer contributed study drug to the APPLE trial. This publication was made possible by the Clinical and Translational Science Collaborative of Cleveland, UL1TR000439 from the National Center for Advancing Translational Sciences (NCATS) component of the National Institutes of Health and NIH roadmap for Medical Research. Its contents are solely the responsibility of the authors and do not necessarily represent the official views of the NIH.

Competing interests None.

Provenance and peer review Not commissioned; externally peer reviewed.

Data sharing statement Unpublished data from the original APPLE study and serum 25-hydroxyvitamin $D$ levels from this secondary analysis are available to the APPLE Investigators and those who apply for data through the APPLE Investigators

Open Access This is an Open Access article distributed in accordance with the Creative Commons Attribution Non Commercial (CC BY-NC 3.0) license, which permits others to distribute, remix, adapt, build upon this work noncommercially, and license their derivative works on different terms, provided the original work is properly cited and the use is non-commercial. See: http:// creativecommons.org/licenses/by-nc/3.0/

\section{REFERENCES}

1. Nossent J, Cikes N, Kiss E, et al. Current causes of death in systemic lupus erythematosus in Europe, 2000-2004: relation to disease activity and damage accrual. Lupus 2007;16:309-17.

2. Manzi S, Meilahn EN, Rairie JE, et al. Age-specific incidence rates of myocardial infarction and angina in women with systemic lupus erythematosus: comparison with the Framingham Study. Am J Epidemiol 1997;145:408-15.

3. Esdaile JM, Abrahamowicz M, Grodzicky T, et al. Traditional Framingham risk factors fail to fully account for accelerated atherosclerosis in systemic lupus erythematosus. Arthritis Rheum 2001;44:2331-7.

4. Westerweel PE, Luyten RK, Hoomans HA, et al. Premature atherosclerotic cardiovascular disease in systemic lupus erythemarosus. Arthritis Rheum 2007;56:1384-96.

5. Kienrich K, Tomaschitz A, Verheyen N, et al. Vitamin D and cardiovascular disease. Nutrients 2013;5:3005-21.

6. DiRosa M, Malaguarnera G, DeGregorio C, et al. Immuno-modulatory effects of vitamin D3 in human monocyte and macrophages. Cell Immunol 2012;280:36-43.

7. Ruiz-Irastorza G, Egurbide MV, Olivares N, et al. Vitamin D deficiency in systemic lupus erythematosus: prevalence, predictors and clinical consequences. Rheumatology 2008;47:920-3.

8. Kamen DL, Cooper GS, Bouali H, et al. Vitamin D deficiency in systemic lupus erythematosus. Autoimmunity Rev 2006;5:114-17.

9. Wright TB, Shults J, Leonard MB, et al. Hypovitaminosis D is associated with greater body mass index and disease activity in pediatric systemic lupus erythematosus. J Pediatr 2009;155:260-5.

10. Borba VZC, Vieira JGH, Kasamatsu T, et al. Vitamin D deficiency in patients with active systemic lupus erythematosus. Osteoporosis Int 2009;20:427-33.

11. Robinson AB, Thierry-Palmer M, Gibson KL, et al. Disease activity, proteinuria, and vitamin $D$ status in children with systemic lupus erythematosus and juvenile dermatomyositis. J Pediatr 2012;160:297-302. 
12. Adams JS, Hewison M. Unexpected actions of vitamin D: new perspectives on the regulation of innate and adaptive immunity. Nat Clin Pract Endocrinol Metab 2008:4:80-90.

13. Piemonti L, Monti P, Sironi M, et al. Vitamin D3 affects differentiation, maturation, and function of human monocyte-derived dendritic cells. J Immunol 2000;164:4443-51.

14. D'Ambrosio D, Cippitelli M, Cocciolo MG, et al. Inhibition of IL-12 production by 1,25 -dihydroxyvitamin D3. Involvement of NF-kappaB downregulation in transcriptional repression of the p40 gene. J Clin Invest 1998;101:252-62.

15. Chen S, Sims GP, Chen XX, et al. Modulatory effects of 1,25-dihydroxyvitamin D3 on human B cell differentiation. J Immuno 2007;179:1634-47.

16. Ronnblom L, Pascual V. The innate immune system in SLE: type I interferons and dendritic cells. Lupus 2008;17:394-9.

17. Wang TJ, Pencina MJ, Booth SL, et al. Vitamin D deficiency and risk of cardiovascular disease. Circulation 2008;117:503-11.

18. Schwartz JB. Effects of vitamin D supplementation in atorvastatin-treated patients: a new drug interaction with an unexpected consequence. Clin Pharmacol Ther 2009;85:198-203.

19. Schanberg LE, Sandborg C, Barnhart HX, et al. Use of atorvastatin in systemic lupus erythematosus in children and adolescents. Arthritis Rheum 2012;64:285-96.

20. Schanberg LE, Sandborg C, Barnhart HX, et al. Premature atherosclerosis in pediatric systemic lupus erythematosus: risk factors for increased carotid intima-media thickness in the atherosclerosis prevention in pediatric lupus erythematosus cohort. Arthritis Rheum 2009;60:1496-507.
21. Petri M, Bello KJ, Fang $\mathrm{H}$, et al. Vitamin $\mathrm{D}$ in systemic lupus erythematosus: modest association with disease activity and the urine protein-to-creatinine ratio. Arthritis Rheum 2013;65:1865-71.

22. Kiani AN, Fang $\mathrm{H}$, Magder LS, et al. Vitamin D deficiency does not predict progression of coronary artery calcium, carotid intima-media thickness or high-sensitivity C-reactive protein in systemic lupus erythematosus. Rheumatology 2013;52:2071-6.

23. Lee SS, Singh S, Magder LS, et al. Predictors of high sensitivity $\mathrm{C}$-reactive protein levels in patients with systemic lupus erythematosus. Lupus 2008;17:114-23.

24. Mochizuki T, Aotsuka S, Satoh T. Clinical and laboratory features of lupus patients with complicating pulmonary disease. Respir Med 1999;93:95-101.

25. Moutsopoulos HM, Mavridis AK, Acritidis NC, et al. High C-reactive protein response in lupus polyarthritis. Clin Exp Rheumatol 1983;1:53-5.

26. Liou LB. Serum and in vitro production of IL-1 receptor antagonist correlate with C-reactive protein levels in newly diagnosed, untreated lupus patients. Clin Exp Rheumatol 2001;19:515-23.

27. Robinson AB, Tangpricha V, Yow E, et al. for the APPLE Investigators. Vitamin D status is a determinant of the effect of atorvastatin on carotid intima medial thickening progression rate in children with lupus: An APPLE substudy. Pediatric Rheumatology Symposium of the American College of Rheumatology, 3-6 April 2014, Orlando, FL, USA, 31.

28. Ross AC, Judd $\mathrm{S}$, Kumari $\mathrm{M}$, et al. Vitamin $\mathrm{D}$ is linked to carotid intima-media thickness and immune reconstitution in HIV-positive individuals. Antivir Ther 2011:16:555-63. 